\title{
HUBUNGAN KUALITAS PERNIKAHAN DENGAN KEBAHAGIAAN DAN KEPUASAN HIDUP PRIBADI: STUDI PADA INDIVIDU DENGAN USIA PERNIKAHAN DI BAWAH LIMA TAHUN DI BANDUNG
}

\author{
Lenny Kendhawati, Fredrick Dermawan Purba
}

\author{
Fakultas Psikologi, Universitas Padjadjaran \\ Jl. Raya Bandung Sumedang KM 21, Jatinangor, Sumedang, Indonesia 45363 \\ lenny.kendhawati@unpad.ac.id
}

\begin{abstract}
Marriage is proven to be related to health and well-being of those involved in it. However, the status of marriage is not the most important, but how the quality of the marriage is the key to its positive effects. This study aims to examine a relationship between marital quality with happiness and life satisfaction. Data collection was conducted on 189 participants who have married with less than five years, said to be a critical period, which are living in the city of Bandung. The marital quality was measured using the Quality Marriage Index/QMI (6 items; $\alpha=.91$ ), happiness was measured using the Happiness Thermometer at three time points ( 3 items; $\alpha=.83$ ), and life satisfaction was measured using the Self-Anchoring Cantril Striving Scale at three time points ( 3 items; $\alpha=$ .47). The Spearman correlation test found that there was a significant positive relationship between the marital quality and happiness at three time points: today ( $\mathrm{rs}=0.431)$, last month ( $\mathrm{rs}=0.409)$, and throughout life ( $\mathrm{rs}=$ 0.415 ) and life satisfaction at two time points: now ( $\mathrm{rs}=0.460)$ and next five years $(\mathrm{rs}=0.281)$. In addition, life satisfaction of five years ago when subjects were still single was reported to be significantly lower compare to their life satisfaction this moment and predicted five years from now $(p<0.001)$. These findings suggest that married couple giving more attention to improving the quality of their marriage relationship in order to be happier and satisfied with their life.
\end{abstract}

Keywords: marital quality; happiness; life satisfaction

\begin{abstract}
Abstrak
Pernikahan terbukti berhubungan dengan kesehatan dan kesejahteraan mereka yang terlibat di dalamnya. Akan tetapi, bukan semata-mata status menikah yang penting, melainkan bagaimana kualitas pernikahan tersebut yang menjadi kunci efek positifnya. Penelitian ini bertujuan menemukan hubungan antara kualitas pernikahan dengan kebahagiaan dan kepuasan hidup. Pengambilan data dilakukan pada 189 partisipan yang berstatus menikah dengan usia pernikahan di bawah lima tahun, dikatakan sebagai masa kritis, yang berdomisili di kota Bandung. Kualitas pernikahan diukur dengan Quality Marriage Index/QMI (6 item; $\alpha=0,91$ ), kebahagiaan diukur dengan Termometer Kebahagiaan pada tiga titik waktu (3 item; $\alpha=0,83$ ), dan kepuasan hidup dengan Self-Anchoring Cantril Striving Scale pada tiga titik waktu ( 3 item; $\alpha=0,47)$. Uji korelasi Spearman menemukan bahwa terdapat hubungan positif yang signifikan antara kualitas pernikahan dengan kebahagiaan di tiga titik waktu: hari ini $(\mathrm{rs}=0,431)$, bulan lalu ( $\mathrm{rs}=0,409)$ dan sepanjang hidup ( $\mathrm{rs}=0,415)$ dan kepuasan hidup di dua titik waktu: saat ini $(\mathrm{rs}=0,460)$ dan lima tahun yang akan datang ( $\mathrm{rs}=0,281)$. Selain itu, kepuasan hidup lima tahun lalu saat belum menikah dilaporkan lebih rendah secara signifikan dibanding kepuasan hidup saat sekarang telah menikah dan juga prediksi kepuasan hidup di masa depan $(p<0,001)$. Temuan ini mendukung pentingnya pasangan pernikahan memberikan perhatian lebih untuk meningkatkan kualitas hubungan pernikahan mereka untuk dapat menjadi lebih bahagia dan puas dengan hidupnya pribadi.
\end{abstract}

Kata kunci: kualitas pernikahan; kebahagiaan; kepuasan hidup

\section{PENDAHULUAN}

Setiap orang secara alamiah ingin bahagia dan berhak untuk bahagia, dan kebutuhan untuk berbahagia menjadi kebutuhan yang penting
(Howell et al., 2016). Lebih dari itu, kebahagiaan bahkan disarankan untuk dijadikan tujuan dalam kebijakan publik (Veenhoven, 2004). Kebahagiaan sendiri didefinisikan berbeda oleh berbagai ahli, 
misalnya: "merasa baik - menikmati hidup dan menginginkan perasaan ini untuk dipertahankan" (Layard, 2011), "rasio perasaan positif dan negatif yang tinggi" (DeWall \& Myers, 2015), atau "kenikmatan secara menyeluruh dalam keseluruhan hidup" (Veenhoven, 2012). Penelitian-penelitian sebelumnya menemukan berbagai efek positif dari berbahagia, antara lain lebih rendah kemungkinannya untuk mengidap penyakit jantung koroner (Davidson, Mostofsky, \& Whang, 2010), lebih rendah mengalami rasa sakit dalam penyakit kronis (Zautra, Johnson, \& Davis, 2005) dan memiliki usia harapan hidup lebih panjang (Steptoe \& Wardle, 2011).

Kepuasan hidup (life satisfaction) sering kali dipertukarkan penggunaannya dengan kebahagiaan. Penelitian ini mengambil posisi membedakan keduanya: kebahagiaan lebih terkait dengan komponen afektif/emosi, sementara kepuasan hidup lebih melibatkan komponen kognitif. Kepuasan hidup didefinisikan oleh Diener dan Diener sebagai "evaluasi subjektif dari kualitas keseluruhan hidup" (Diener \& Diener, 2009). Berbagai penelitian sebelumnya menemukan bahwa kepuasan hidup berhubungan dengan resiliensi, perilaku sehat, kesehatan fisik dan kesehatan mental, dan keberhargaan diri (Beutel, Glaesmer, Decker, Fischbeck, \& Brähler, 2009; Grant, Wardle, \& Steptoe, 2009).

Berbagai faktor yang mempengaruhi kebahagiaan dan kepuasan hidup telah banyak diteliti oleh para ahli: mulai dari yang makro seperti tingkat kemakmuran negara sampai personal seperti kesehatan fisik dan lainnya (lihat sebagai contoh (Boyce, Brown, \& Moore, 2010; Proctor, Linley, \& Maltby, 2009; Shin \& Sok, 2012; Veenhoven, 2012). Penelitian ini berfokus pada salah satu faktor yang dinilai penting, terutama oleh masyarakat Indonesia, yaitu pernikahan.

Pernikahan merupakan bentuk interaksi antara laki-laki dan perempuan yang sifatnya paling intim dan perlu dipertahankan (Duvall,
1977). Duval \& Miller (1977) menjelaskan lebih lanjut mengenai pernikahan yang didefinisikan sebagai hubungan yang diakui secara sosial antara pria dan wanita yang melibatkan hubungan seksual, keabsahan kepemilikan anak, dan melakukan pembagian kerja atau peran sebagai suami istri. Menurut Pasal 1 Undang-Undang Republik Indonesia Nomor 1 Tahun 1974 tentang Perkawinan menyatakan bahwa perkawinan adalah ikatan lahir dan batin antara seorang pria dan wanita sebagai suami istri dengan tujuan membentuk keluarga atau rumah tangga yang bahagia dan kekal berdasarkan Ketuhanan Yang Maha Esa.

Berbagai studi menemukan sumbangsih pernikahan dengan kesehatan, khususnya kesehatan mental dan kesejahteraan. Mereka yang menikah adalah lebih sehat dan puas dengan hidup mereka (Fu \& Noguchi, 2016), lebih sedikit melaporkan bahwa mereka mengalami depresi dan melaporkan kesejahteraan psikologis dan emosional yang lebih baik dibandingkan mereka yang lajang dan bercerai (Koball, Moiduddin, Henderson, Goesling, \& Besculides, 2010). Penelitianpenelitian terbaru menyelidiki lebih dalam dan menemukan bahwa bukan status relasi intimnya (misalnya menikah, berpacaran) yang menjadi penentu kesehatan dan kesejahteraan individu, melainkan kualitas relasinya (Robles, Slatcher, Trombello, \& McGinn, 2014). Norton (1983) mendefinisikan kualitas pernikahan sebagai hasil evaluasi subjektif dari suami atau istri terhadap situasi yang dialami selama pernikahannya berlangsung, dilihat dari seberapa stabil, kuat, menyenangkan, membentuk perasaan sebagai satu kesatuan, dan memuaskan (Norton, 1983).

Lima tahun pertama pernikahan adalah masamasa kritis dan dikatakan juga sebagai pusat pernikahan. Pendapat ini didasari bahwa dalam lima tahun pertama terdapat banyak dinamika baru terkait kehidupan pernikahan, seperti masuknya seseorang ke dalam kehidupan pernikahan, kehadiran anak pertama, dan membesarkan anak pertama . 
Masa lima tahun pertama ini juga penting karena menentukan bagaimana pernikahan akan berlangsung ke depannya. Pada lima tahun pertama, penyesuaian dan ekspektasi seseorang sebelum menikah akan diuji, serta mereka juga akan belajar bagaimana cara mereka dalam menghadapi krisis atau konflik. Meskipun konflik-konflik yang muncul di awal pernikahan berbeda pada setiap pasangan, disebutkan beberapa sumber konflik pasangan yang biasanya muncul di awal pernikahan, seperti kebiasaan yang berbeda, finansial, ekspektasi sebelum menikah, kepuasan seksual, masalah keluarga besar, cara pola asuh anak, dan kesibukan di luar rumah (Dewi \& Basti, 2011; Markman, Rhoades, Stanley, Ragan, \& Whitton, 2010). Rentannya lima tahun pertama pernikahan ini ditunjukkan juga dari kasus perceraian yang terjadi di seluruh Indonesia, di mana mayoritas penggugat adalah pasangan dengan usia pernikahan di bawah lima tahun (Era Indonesia, 2018). Konflik yang terjadi dan keberhasilan pasangan dalam menanganinya berdampak pada kualitas pernikahan (Rohmah, Fitriana, \& Rahmatika, 2017). Penggalian literatur di Google Scholar tidak menemukan penelitian yang sudah melaporkan hal yang sama, baik di Indonesia maupun negara-negara lainnya.

Penelitian ini bertujuan untuk menemukan bagaimana hubungan antara kualitas pernikahan dengan kebahagiaan dan kepuasan hidup individu yang terlibat di dalam pernikahan tersebut, khususnya di lima tahun pertama pernikahan yang disebut sebagai masa kritis.

\section{METODE}

\section{Desain Penelitian}

Desain penelitian yang digunakan dalam penelitian ini merupakan penelitian kuantitatif non-eksperimental dengan metode survei.

\section{Partisipan Penelitian}

Teknik pengambilan sampel dalam penelitian ini menggunakan non-probability sampling dengan bentuk purposive sampling. Karakteristik sampel adalah sebagai berikut: individu yang telah menikah dengan usia pernikahan di bawah lima tahun, tinggal di Kota Bandung, dan bersedia berpartisipasi dalam penelitian yang dibuktikan dengan menandatangani formulir kesediaan (informed consent). Pengambilan data penelitian dilakukan selama dua bulan, yakni Januari hingga Februari 2018. Dua orang pewawancara adalah mahasiswa tahun terakhir Fakultas Psikologi Universitas Padjadjaran.

Partisipan yang datanya berhasil dikumpulkan untuk dianalisis berjumlah 189 orang. Mayoritas dari mereka adalah perempuan $(61,4 \%)$, suku bangsa Sunda (76,7\%), beragama Islam (96,3\%), berpendidikan tinggi $(52,4 \%)$, dan penghasilan bulanan berkisar antara $\mathrm{Rp}$ 2.5000.000 sampai Rp 5.000.000. Rerata usia partisipan dalam penelitian ini adalah 27,9 tahun dengan usia pernikahan 2,4 tahun. Detail dapat dilihat di Tabel 1.

\section{Alat Ukur \\ Data sosio-demografi dalam penelitian ini dikumpulkan dengan menggunakan kuesioner terstruktur yang berisi sejumlah pertanyaan, di antaranya terkait jenis kelamin, usia, pendidikan, suku bangsa, agama, usia saat menikah dan usia pernikahan.}

Kualitas pernikahan diukur menggunakan Indeks Kualitas Pernikahan (Quality Marriage Index-QMI) yang disusun oleh Robert Norton (Norton, 1983). Alat ukur ini terdiri dari enam butir pernyataan yang meminta partisipan melaporkan sejauh mana mereka setuju atau tidak setuju dengan pernyataan umum tentang pernikahan mereka (misal: "Kami memiliki pernikahan yang baik"). Lima butir pernyataan meminta pasangan untuk merespons menurut skala Likert tujuh poin ( $1=$ sangat tidak setuju sekali sampai $7=$ =sangat setuju sekali), sedangkan satu butir pernyataan dengan skala sepuluh poin (1=tidak bahagia sampai 10=kebahagiaan yang sempurna). Skor QMI 
adalah total keenam butir pernyataan yang berkisar antara skor 6 hingga 45. Skor yang lebih tinggi mencerminkan kualitas pernikahan yang lebih tinggi. Penelitian sebelumnya menemukan nilai reliabilitas $\mathrm{QMI}=0,93$ (Rohmah et al., 2017) sementara pada penelitian ini nilai reliabilitas diperoleh sebesar 0,91 .

Tabel 1.

Karakteristik Sosio-Demografi Partisipan

\begin{tabular}{|c|c|c|c|}
\hline \multicolumn{2}{|r|}{ Karakteristik } & \multirow{2}{*}{$\frac{\text { Jumlah }}{73}$} & \multirow{2}{*}{$\begin{array}{l}\% \\
38,6\end{array}$} \\
\hline Jenis Kelamin & Laki-laki & & \\
\hline & Perempuan & 116 & 61,4 \\
\hline \multirow[t]{5}{*}{ Suku bangsa } & Sunda & 145 & 76,7 \\
\hline & Jawa & 26 & 13,8 \\
\hline & Suku asal Jawa lainnya & 3 & 1,6 \\
\hline & Suku asal Sumatera & 12 & 6,3 \\
\hline & Lainnya & 3 & 1,6 \\
\hline \multirow[t]{3}{*}{ Agama } & Islam & 182 & 96,3 \\
\hline & Kristen $^{\mathrm{a}}$ & 6 & 3,2 \\
\hline & Lainnya & 2 & 1,1 \\
\hline \multirow[t]{3}{*}{ Pendidikan } & Sekolah Dasar & 1 & 0,5 \\
\hline & Sekolah Menengah ${ }^{\mathrm{b}}$ & 89 & 47,1 \\
\hline & Universitas $^{\mathrm{c}}$ & 99 & 52,4 \\
\hline \multirow[t]{6}{*}{ Pendapatan $^{\mathrm{d}}$} & Tidak berpenghasilan & 29 & 15,3 \\
\hline & $<500.000$ & 0 & 0,0 \\
\hline & $500.000-2.500 .000$ & 44 & 23,3 \\
\hline & $2.500 .000-5.000 .000$ & 77 & 40,7 \\
\hline & $5.000 .000-10.000 .000$ & 26 & 13,8 \\
\hline & $>10.000 .000$ & 13 & 6,9 \\
\hline
\end{tabular}

Kebahagiaan pribadi partisipan diukur dengan Termometer Kebahagiaan (Happiness thermometer), yaitu sebuah skala 11 poin untuk penilaian kebahagiaan pada tiga titik waktu: hari ini, bulan lalu, dan secara keseluruhan seumur hidup. Termometer kebahagiaan ini disusun oleh 11 gambar wajah tersenyum (smileys) yang disajikan secara horizontal, mulai dari 0 , diwakili oleh 'wajah sedih', hingga 5, diwakili oleh 'wajah netral', ke 10, diwakili oleh 'wajah tersenyum'. Alat ukur ini terbukti memiliki reliabilitas test-retest yang baik, koefisien validitas konvergen yang signifikan, dan kemampuan untuk menemukan perbedaan kecil dalam kebahagiaan (Baptista et al., 2016). Saat digunakan di Indonesia, nilai konsistensi internalnya adalah 0,78 (Purba et al., 2018). Untuk sampel penelitian ini, konsistensi internal dari skala termometer kebahagiaan adalah 0,83 .

Kepuasan hidup dinilai dengan SelfAnchoring Cantril Striving Scale (Bjørnskov, 2010). Pada partisipan disajikan sebuah tangga vertikal yang memiliki 11 anak tangga, di mana anak tangga terbawah ditandai dengan nilai 0 (kehidupan terburuk), dan anak tangga teratas ditandai dengan nilai 10 (kehidupan terbaik). Partisipan diminta untuk menilai seberapa besar mereka merasa puas dengan hidup mereka di tiga titik waktu: sekarang, 5 tahun lalu, dan 5 tahun dari sekarang. Alat ukur ini sering digunakan dalam survei seperti Gallup World Poll (Bjørnskov, 2010). Saat digunakan di 
Indonesia, nilai konsistensi internalnya adalah 0,74 (Purba et al., 2018). Untuk sampel penelitian ini, konsistensi internal dari skala termometer kebahagiaan adalah 0,47.

\section{Analisis Statistik}

Data sosio-demografi dianalisis dengan: (i) persentase untuk data sosio-demografi seperti jenis kelamin, suku bangsa, agama, pendidikan, dan pendapatan, (ii) rerata dan simpangan baku untuk data usia, usia saat menikah, dan usia pernikahan. Uji ShapiroWilk digunakan untuk mengecek apakah data kualitas pernikahan, kebahagiaan, dan kepuasan hidup terdistribusi normal dan ditemukan bahwa data tidak terdistribusi normal. Uji korelasi Rank Spearman kemudian dilakukan untuk melihat hubungan antara kualitas pernikahan dengan kebahagiaan dan kepuasan hidup individual partisipan. Koefisien korelasi Spearman rho $\left(\mathrm{r}_{\mathrm{s}}\right)$ yang diperoleh diinterpretasi berdasarkan kriteria dari Cohen, yaitu: $0,1=$ kecil, 0,3=sedang, dan 0,5=besar (Cohen, 1988). $P$ - value kurang dari 0,05 dianggap signifikan secara statistik.

\section{HASIL DAN PEMBAHASAN}

Tabel 2 mempresentasikan hasil statistik deskripsi setiap variabel dalam penelitian ini. Secara umum dapat dilihat bahwa kualitas pernikahan, kebahagiaan individu partisipan hari ini pada tiga titik waktu (hari ini, bulan lalu, dan sepanjang hidup) dan kepuasan hidup partisipan saat ini dan lima tahun yang akan datang cukup tinggi. Yang paling rendah di antara lainnya adalah kepuasan hidup partisipan lima tahun lalu. Uji Anova tidak menemukan perbedaan rerata skor kualitas pernikahan, kebahagiaan dan kepuasan hidup pribadi antara kelompok-kelompok faktor sosio-demografi: jenis kelamin, suku bangsa, agama, pendidikan, dan pendapatan. Ini menunjukkan bahwa kualitas pernikahan, kebahagiaan, dan kepuasan hidup tidak dipengaruhi oleh perbedaan faktor-faktor demografi.

Tabel 2.

Hasil Statistik Deskripsi Setiap Variabel

\begin{tabular}{|c|c|c|c|c|c|}
\hline \multirow{2}{*}{\multicolumn{2}{|c|}{ Variabel }} & & Simpangan & Skor & Skor \\
\hline & & & & & Maksimum \\
\hline \multicolumn{2}{|c|}{ Kualitas Pernikahan } & 38,41 & 5,46 & 21 & 45 \\
\hline \multirow[t]{3}{*}{ Kebahagiaan } & Hari ini & 8,27 & 1,50 & 5 & 10 \\
\hline & Bulan lalu & 7,89 & 1,57 & 3 & 10 \\
\hline & Sepanjang hidup & 8,48 & 1,40 & 4 & 10 \\
\hline \multirow{3}{*}{$\begin{array}{l}\text { Kepuasan } \\
\text { hidup }\end{array}$} & Saat ini & 7,45 & 1,54 & 1 & 10 \\
\hline & Lima tahun lalu & 5,75 & 1,91 & 0 & 10 \\
\hline & Lima tahun yang akan datang & 9,20 & 1,18 & 2 & 10 \\
\hline
\end{tabular}

Tabel 3.

Korelasi antara Kebahagiaan dan Kepuasan Hidup dengan Kualitas Pernikahan

\begin{tabular}{llll}
\hline Aspek & Jangka waktu & \multicolumn{2}{l}{ Kualitas Pernikahan } \\
\cline { 3 - 4 } & & Rho & p-value \\
\hline Kebahagiaan & Hari ini & 0,431 & $<0,001$ \\
& Bulan lalu & 0,409 & $<0,001$ \\
& Sepanjang hidup & 0,415 & $<0,001$ \\
Kepuasan hidup & Saat ini & 0,460 & $<0,001$ \\
& Lima tahun lalu & 0,077 & 0,291 \\
& Lima tahun yang akan datang & 0,281 & $<0,001$ \\
\hline
\end{tabular}


Tabel 3 memaparkan hasil uji korelasi antara kualitas pernikahan dengan kebahagiaan dan kepuasan hidup individu yang menjalani pernikahan dengan usia pernikahan di bawah lima tahun. Kualitas pernikahan berhubungan signifikan positif dengan kebahagiaan partisipan di tiga titik waktu: hari ini $\left(\mathrm{r}_{\mathrm{s}}=0,431\right)$, bulan lalu $\left(\mathrm{r}_{\mathrm{s}}=0,409\right)$ dan sepanjang hidup $\left(r_{s}=0,415\right)$. Artinya, semakin tinggi kualitas pernikahan yang dialami oleh seorang individu, semakin tinggi kebahagiaan pribadi yang ia rasakan. Ketiganya dapat dikatakan berhubungan dalam derajat sedang menuju besar.

Hasil uji korelasi antara kualitas pernikahan dengan kepuasan hidup dari partisipan penelitian ini juga kurang lebih serupa dengan kebahagiaan: kualitas pernikahan berhubungan positif yang signifikan dengan kepuasan hidup saat ini $\left(\mathrm{r}_{\mathrm{s}}=0,460\right)$ dan lima tahun yang akan datang $\left(r_{s}=0,281\right)$. Hubungan antara kualitas pernikahan dengan kepuasan hidup saat ini tergolong sedang ke besar, sementara dengan lima tahun yang akan datang tergolong kecil ke sedang. Hasil berbeda ditampilkan untuk kepuasan hidup lima tahun yang lalu: tidak terdapat hubungan yang signifikan antara kualitas pernikahan dengan kepuasan hidup lima tahun lalu $\left(r_{s}=0,077\right)$.

Hasil dari penelitian ini secara umum menunjukkan bahwa kualitas pernikahan berhubungan signifikan positif dengan kebahagiaan dan kepuasan hidup. Hal ini sejalan dengan beberapa penelitian sebelumnya di berbagai belahan dunia, misalnya di Norwegia (Dyrdal, Roysamb, Nes, \& Vitterso, 2011), dan India (Khajeh, Goodarzi, \& Soleimani, 2014). Pada masa kritis lima tahun pertama pernikahan yang rentan konflik, individu dan pasangan pernikahannya menilai bahwa pernikahan mereka baik, stabil, kuat, memuaskan, dan mereka dapat bekerja sebagai tim, keduanya dapat secara optimal mengekspresikan cinta dan kasih sayang mereka dan pada akhirnya meningkatkan kebahagiaan dan kesejahteraan mereka pribadi (Khajeh, Goodarzi, \&
Soleimani, 2014). Tidak hanya kepuasan hidup saat ini, hubungan pernikahan yang berkualitas bahkan berhubungan dengan antisipasi masa depan lima tahun mendatang. Penelitian lain terkait kualitas pernikahan dan pola asuh menunjukkan pasangan yang memiliki kualitas relasi pernikahan tinggi menampilkan pola asuh yang hangat, peka dan penuh penerimaan terhadap anak mereka, sementara orang tua yang kualitas pernikahannya rendah lebih sering menampilkan pola asuh yang permisif dan hubungan yang negatif (Carlson \& McLanahan, 2006). Sebaliknya, individu yang berada dalam pernikahan yang berkualitas rendah lebih mungkin untuk menampilkan tanda-tanda depresi (Leach, Butterworth, Olesen, \& Mackinnon, 2013). Temuan yang menarik adalah bahwa satusatunya titik waktu kepuasan hidup yang tidak berhubungan signifikan dengan kualitas pernikahan adalah lima tahun lalu, yang adalah sebelum mereka menikah (usia pernikahan maksimum adalah lima tahun dalam penelitian ini). Hal ini ditemukan pada semua kelompok dalam semua faktor sosiodemografi (misal: laki-laki dan perempuan). Ketika dibandingkan dengan uji Wilcoxon matched-pairs signed-ranks, kepuasan hidup partisipan lima tahun lalu dengan saat ini dan juga dengan lima tahun mendatang terbukti berbeda signifikan $(p<0,001)$. Hasil ini sejalan dengan penelitian longitudinal di Norwegia yang menemukan bahwa partisipan mereka melaporkan kepuasan hidup yang lebih tinggi saat mereka menikah dibandingkan sebelum menikah (Næss, Blekesaune, \& Jakobsson, 2015).

Temuan penelitian ini mendukung pentingnya pasangan pernikahan memberikan perhatian lebih untuk meningkatkan aspek-aspek dalam hubungan mereka sehingga keduanya mengalami pernikahan yang berkualitas. Aspek-aspek dalam hubungan yang penting, seperti: saling mendukung, komunikasi yang positif, menjalin kedekatan, dan kepedulian (Pateraki \& Roussi, 2013; Rohmah et al., 2017) krusial untuk dikembangkan oleh pasangan. Tidak hanya pasangan saja, tetapi 
pihak-pihak diluar pasangan seperti keluarga besar dan teman juga diharapkan memberikan dukungan (Pateraki \& Roussi, 2013). Jika diperlukan, program-program peningkatan kualitas relasi pasangan pernikahan yang diberikan oleh profesional secara terstruktur dapat menjadi pilihan pasangan untuk diikuti (Blanchard, Hawkins, Baldwin, \& Fawcett, 2009; Halford et al., 2010; Isanezhad, Ahmadi, \& Etemadi, 2010). Ketika usaha yang dilakukan untuk meningkatkan kualitas pernikahan berhasil, maka pasangan menjadi lebih bahagia dan puas dengan hidupnya pribadi. Pada gilirannya, individu yang bahagia dan puas akan hidupnya juga akan menghasilkan pernikahan yang dinilai memuaskan (Asoodeh, Khalili, Daneshpour, \& Lavasani, 2010).

Beberapa keterbatasan penelitian ini perlu diperhatikan. Pertama, teknik sampling yang non-probabilitas menyebabkan keterbatasan generalisasi hasil dari penelitian ini. Kedua, titik waktu yang digunakan dalam kepuasan hidup, yaitu (i) lima tahun yang lalu adalah bersifat retrospeksi dan (ii) lima tahun yang akan datang adalah hipotetis sehingga tidak dapat dihindarkan dari bias. Penelitian selanjutnya dapat mempertimbangkan desain longitudinal. Ketiga, keterbatasan desain dan jumlah partisipan mengakibatkan faktorfaktor yang dapat menjadi moderator ataupun mediator hubungan antara kedua kualitas pernikahan dengan kebahagiaan dan kepuasan hidup pribadi, seperti misalnya jenis kelamin dan durasi pernikahan, tidak dapat dikontrol dan dianalisis menyeluruh.

\section{SIMPULAN}

Penelitian ini dilakukan pada individu di kota Bandung Indonesia yang menikah dengan usia pernikahan di bawah lima tahun. Ditemukan bahwa terdapat hubungan positif yang signifikan antara kualitas pernikahan dengan kebahagiaan (hari ini, bulan lalu, dan sepanjang hidup) dan kepuasan hidup (saat ini dan lima tahun mendatang) dari individu yang terlibat di dalam pernikahan tersebut. Selain itu, kepuasan hidup lima tahun lalu saat belum menikah dilaporkan lebih rendah secara signifikan dengan kepuasan hidup saat sekarang telah menikah dan juga prediksi kepuasan hidup di masa depan.

\section{UCAPAN TERIMA KASIH}

Penulis mengucapkan terima kasih kepada Dela Aghnia Maraya dan Socha Kenyo Abrifidinar yang dengan tekun mengumpulkan data yang berkualitas.

\section{DAFTAR PUSTAKA}

Asoodeh, M. H., Khalili, S., Daneshpour, M., \& Lavasani, M. G. (2010). Factors of successful marriage: Accounts from self described happy couples. Procedia - Social and Behavioral Sciences, 5, 2042-2046.

https://doi.org/10.1016/j.sbspro.2010.0 $\underline{7.410}$

Baptista, A., Camilo, C., Santos, I., de Almeida Brites, J., Rosa, J. B., \& Fernandez-Abascal, E. G. (2016). What are people saying when they report they are happy or life satisfied. Anales de Psicologia, 32(3), 803-809. doi:http://dx.doi.org/10.6018/analesps. $\underline{32.3 .229121}$

Beutel, M. E., Glaesmer, H., Decker, O., Fischbeck, S., \& Brähler, E. (2009). Life satisfaction, distress, and resiliency across the life span of women. Menopause, 16(6), 1132-1138. doi:10.1097/gme.0b013e3181a857f8

Bjørnskov, C. (2010). How comparable are the gallup world poll life satisfaction data? Journal of Happiness Studies, 11(1), 41-60. doi:10.1007/s10902-0089121-6

Blanchard, V. L., Hawkins, A. J., Baldwin, S. A., \& Fawcett, E. B. (2009). Investigating the effects of marriage and relationship education on couples' communication skills: A meta-analytic 
study. Journal of Family Psychology, 23(2), 203-214. doi:10.1037/a0015211

Boyce, C. J., Brown, G. D. A., \& Moore, S. C. (2010). Money and happiness:Rank of income, not income, affects life satisfaction. Psychological Science, 21(4), 471-475. doi:10.1177/0956797610362671

Carlson, M. J., \& McLanahan, S. S. (2006). Strengthening unmarried families: Could enhancing couple relationships also improve parenting? Social Service Review, 80(2), 297-321.

Cohen, J. (1988). Statistical power analysis for the behavioral sciences $2^{\text {nd }}$ ed. Hillsdale, USA: Erlbaum Associates.

Davidson, K. W., Mostofsky, E., \& Whang, W. (2010). Don't worry, be happy: positive affect and reduced 10-year incident coronary heart disease: the Canadian Nova Scotia Health Survey. European Heart Journal, 31(9), 10651070. doi:10.1093/eurheartj/ehp603

DeWall, C. N., \& Myers, D. G. (2015). Psychology. New York, USA: Macmillan Learning.

Dewi, E. M. P., \& Basti, B. (2011). Konflik perkawinan dan model penyelesaian konflik pada pasangan suami istri. Jurnal Ilmiah Psikologi, 2(1), 42-51.

Diener, E., \& Diener, M. (2009). Crosscultural correlates of life satisfaction and self-esteem. In E. Diener (Ed.), Culture and Well-Being: The Collected Works of Ed Diener (pp. 71-91). Dordrecht: Springer Netherlands.

Duvall, E. M. (1977). Marriage and family development (5 ed.). Philadelphia, USA: Lippincott Co.

Dyrdal, G. M., Roysamb, E., Nes, R. B., \& Vitterso, J. (2011). Can a happy relationship predict a happy life? A population-based study of maternal well-being during the life transition of pregnancy, infancy, and toddlerhood. Journal of Happiness Studies, 12, 947962.

Era Indonesia. (2018). Fakta di balik tingginya angka perceraian di Indonesia. Retrieved from https://www.era.id/read/lYUMBLfakta-di-balik-tingginya-angkaperceraian-di-indonesia

Fu, R., \& Noguchi, H. (2016). Does marriage make us healthier? Inter-country comparative evidence from China, Japan, and Korea. PLOS ONE, 11(2), e0148990.

doi:10.1371/journal.pone.0148990

Grant, N., Wardle, J., \& Steptoe, A. (2009). The relationship between life satisfaction and health behavior: A cross-cultural analysis of young adults. International Journal of Behavioral Medicine, 16(3), 259-268. doi:10.1007/s12529-009-9032-x

Halford, W. K., Wilson, K., Watson, B., Verner, T., Larson, J., Busby, D., \& Holman, T. (2010). Couple relationship education at home: Does skill training enhance relationship assessment and feedback? Journal of Family Psychology, 24(2), 188-196. doi:10.1037/a0018786

Howell, K. H., Coffey, J. K., Fosco, G. M., Kracke, K., Nelson, S. K., Rothman, E. F., \& Grych, J. H. (2016). Seven reasons to invest in well-being. Psychology of Violence, 6(1), 8.

Isanezhad, O., Ahmadi, S., \& Etemadi, A. (2010). Effectiveness of relationship enhancement on marital quality of couples. Journal of Behavioral Sciences, 4(1), 8.

Khajeh, A., Goodarzi, M., \& Soleimani, F. (2014). The relationship of 
psychological well-being with marital quality and the dimensions of the married students. Indian Journal of Science Research, 7(1), 534-538.

Koball, H. L., Moiduddin, E., Henderson, J., Goesling, B., \& Besculides, M. (2010). What do we know about the link between marriage and health? Journal of Family Issues, 31(8), 1019-1040. doi:10.1177/0192513X10365834

Layard, R. (2011). Happiness: Lessons from a new science. London, UK Penguin

Leach, L. S., Butterworth, P., Olesen, S. C., \& Mackinnon, A. (2013). Relationship quality and levels of depression and anxiety in a large population-based survey. Social Psychiatry and Psychiatric Epidemiology, 48(3), 417425. doi:10.1007/s00127-012-0559-9

Markman, H. J., Rhoades, G. K., Stanley, S. M., Ragan, E. P., \& Whitton, S. W. (2010). The premarital communication roots of marital distress and divorce: The first five years of marriage. Journal of Family Psychology, 24(3), 289.

Næss, S., Blekesaune, M., \& Jakobsson, N. (2015). Marital transitions and life satisfaction: Evidence from longitudinal data from Norway. Acta Sociologica, 58(1), 63-78.

Norton, R. (1983). Measuring marital quality: A critical look at the dependent variable. Journal of Marriage and the Family, 141-151.

Pateraki, E., \& Roussi, P. (2013). Marital quality and well-being: The role of gender, marital duration, social support and cultural context. In A. Efklides \& D. Moraitou (Eds.), A Positive Psychology Perspective on Quality of Life (pp. 125-145). Dordrecht: Springer Netherlands.
Proctor, C. L., Linley, P. A., \& Maltby, J. (2009). Youth life satisfaction: A review of the literature. Journal of Happiness Studies, 10(5), 583-630. doi:10.1007/s10902-008-9110-9

Purba, F. D., Hunfeld, J. A. M., Fitriana, T. S., Iskandarsyah, A., Sadarjoen, S. S., Busschbach, J. J. V., \& Passchier, J. (2018). Living in uncertainty due to floods and pollution: the health status and quality of life of people living on an unhealthy riverbank. BMC Public Health, $18(1), \quad 782$. doi:10.1186/s12889-018-5706-0

Robles, T. F., Slatcher, R. B., Trombello, J. M., \& McGinn, M. M. (2014). Marital quality and health: A meta-analytic review. Psychological Bulletin, 140(1), 140-187.

Rohmah, Z. H., Fitriana, T. S., \& Rahmatika, R. (2017). Marital quality in early years marriage: The role of intimacy, passion and commitment. UI Proceedings on Social Science and Humanities, 1.

Shin, S. H., \& Sok, S. R. (2012). A comparison of the factors influencing life satisfaction between Korean older people living with family and living alone. International Nursing Review, 59(2), 252-258. doi:10.1111/j.14667657.2011.00946.x

Steptoe, A., \& Wardle, J. (2011). Positive affect measured using ecological momentary assessment and survival in older men and women. Proceedings of the National Academy of Sciences, 108(45), 18244. doi:10.1073/pnas.1110892108

Veenhoven, R. (2004). Happiness as a public policy aim: The greatest happiness principle. In P. A. Linley \& S. Joseph (Eds.), Positive Psychology in Practice (pp. 658-678). New Jersey, USA: John Wiley \& Sons, Inc. 
Veenhoven, R. (2012). Happiness: Also known as "Life satisfaction" and "Subjective well-being". In K. C. Land, A. C. Michalos, \& M. J. Sirgy (Eds.), Handbook of Social Indicators and Quality of Life Research (pp. 63-77). Dordrecht: Springer Netherlands.
Zautra, A. J., Johnson, L. M., \& Davis, M. C. (2005). Positive affect as a source of resilience for women in chronic pain. Journal of Consulting and Clinical Psychology, 73(2), 212-220. doi:10.1037/0022-006X.73.2.212 